Research Article

\title{
Systematic Pan-Cancer Population-Based Analysis Reveals the Incidence and Prognosis of Lung Metastases at Diagnosis
}

\author{
Xiaohong Liang, Yinan Cheng, Weijun Zhou, Jun Ni, Yuqing Li, and Gaohua Feng (iD \\ Department of Pulmonary and Critical Care Medicine, \\ Zhangjiagang TCM Hospital Affiliated to Nanjing University of Chinese Medicine, No. 4, Kangle Road, Zhangjiagang City, \\ Jiangsu Province, China
}

Correspondence should be addressed to Gaohua Feng; zjgzy069@njucm.edu.cn

Received 4 March 2021; Accepted 3 June 2021; Published 16 June 2021

Academic Editor: Claudia Marchetti

Copyright (c) 2021 Xiaohong Liang et al. This is an open access article distributed under the Creative Commons Attribution License, which permits unrestricted use, distribution, and reproduction in any medium, provided the original work is properly cited.

\begin{abstract}
Background. Metastasis is one of the most prevalent causes of death in cancer patients and the lungs are among the organs most commonly affected by metastasis. However, analysis of the incidence and prognosis of lung metastasis (LM) based on primary cancer sites is lacking. Methods. We enrolled cancer patients with LM from the Surveillance, Epidemiology, and End Results (SEER) database. The risk factors for LM were determined using multivariate logistics regression. Forest plots were used to compare the impact of with LM versus without LM alone among different primary caner site subgroups. Results. Among 1,525,441 cases, 47,537 presented with LM at initial diagnosis. Multivariate logistics regression revealed that male sex, older age, later T/N stage, unmarried status, and lack of insurance were risk factors for LM. The incidence of LM was $11.91 \%$ in bone cancer and $11.19 \%$ in pancreatic cancer. In terms of the distribution of primary cancers, $19.22 \%$ of LMs originated from the colon and rectum, with 11.63\% from the kidneys. The median survival for LM cases was 6 months, with the best survival in testicular cancer (19 months) and bone cancer (12 months). Patients with LM had higher hazard ratio (HR) for mortality compared to those without LM, except for those with primary cancer in the brain $(P=0.09)$. We stratified patients by primary cancer site, and subgroup analyses showed that LM had a significant negative impact on survival. The most significant was in thyroid cancer $(\mathrm{HR}=44.79)$, followed by melanoma $(H R=24.26)$, prostate $(H R=16.0)$, breast $(H R=13.46)$, endometrial $(H R=12.64)$, testicular $(H R=12.31)$, and kidney $(\mathrm{HR}=11.33)$ cancer (all $P<0.001)$. Conclusion. Patients presenting with LM had higher HR for mortality compared to those without LM, except for those with brain tumor. Clinicians should pay more attention to the occurrence of LM, especially in patients with a significantly increased HR for mortality, such as those with thyroid cancer, melanoma, and prostate cancer.
\end{abstract}

\section{Background}

Cancer has been one of the main global health problems over the years and so far has been the second primary public death cause. In 2020, it was reported that there were $1,806,590$ new cancer cases and 606,520 cancer deaths in the USA [1]. Metastatic disease represents the most prevalent cause of cancer-related death [2]. Among the vital organs to which solid tumors metastasize, the lungs are among the most commonly affected, ranging from $20 \%$ to $45 \%$ [3].

Due to the ongoing development of new treatments and better survival outcomes over the years, the trend may continue to increase. Most lung metastasis (LM) is detected incidentally without symptoms or with nonspecific symptoms. Treatment of LM requires a comprehensive approach. Surgical resection can be performed in suitable cases. Good survival outcomes have been demonstrated in patients with many different primary cancers who underwent pulmonary metastasectomy [4]. Data from the International Registry of Lung Metastases show that, for various histological types of tumors, the 5-, 10-, and 15-year survival rates after complete resection of metastases were $36 \%, 26 \%$, and $22 \%$, respectively [4]. If LM is not suitable for surgical resection, radiotherapy and chemotherapy can be used.

Different tumors have their own proclivity to metastasize to target organs. LM is most common from primary breast, 
colon, prostate, and bladder cancers, neuroblastoma, and sarcoma [5]. When cancer cells leave their primary site and migrate to the lungs, they change from quiescence into metastatic outgrowth and infiltrate surrounding tissues. At the same time, the environment of local blood flow, hypoxia, and inflammation in the lungs accelerates this pathophysiological process. LM develops due to various mechanisms, including local blood flow and cellular or biochemical properties of the tumor cells. Although LM and its associated mortality have a high incidence, the potential mechanisms by which metastatic tumor cells grow and thrive in the lung microenvironment remain elusive.

Many of the current studies [6-9] on LM are on single primary tumors, and a generalized analysis of LM is lacking. In the current study, we used the Surveillance, Epidemiology, and End Results (SEER) database to perform a comprehensive analysis to check the status of LM. The study was designed to show a generalizable recognition of the incidence and prognosis of LM across multiple types of cancer. We also analyzed the epidemiological trends by clinicopathological factors to explain the potential disparities among patients, including biological factors (age, sex, $\mathrm{T}$ stage, and $\mathrm{N}$ stage) and socioeconomic factors (race, insurance, and marriage). These data may assist in clinical decision-making concerning lung-specific surveillance and provide epidemiological evidence for the estimation of disease burden for both policy-makers and healthcare service providers.

\section{Materials and Methods}

2.1. Data Source. Our study was based on the SEER cancer registry, which is the population-based registry for cancer incidence in the USA and a publicly available and reliable database. All the information was obtained using SEER * Stat version 8.3.8. Currently, it documents the cancer cases from 18 registry sites, encompassing roughly $28 \%$ of the general population in USA. After obtaining permission, the research files were extracted from the SEER database and there was no need for informed consent.

2.2. Patient Selection. We enrolled patients diagnosed with only one primary cancer using positive histology between January 1, 2010, and December 31, 2016. Cases that originated in the lungs and those with unknown LM status were excluded, along with cases without survival information. $\mathrm{Pa}$ tients diagnosed with T0 or Tis stage based on the American Joint Committee on Cancer (AJCC) 7th TNM staging system and cases within situ were also removed. In addition, the SEER database provides clinical variables, including age at diagnosis, sex, race, $\mathrm{T}$ and $\mathrm{N}$ stages, race, marital status, instance, and primary cancer sites. Overall survival (OS) time was obtained from the SEER database. Age at diagnosis was categorized into three groups: young ( $\leq 45$ years); middleaged ( $45-75$ years); and elderly ( $\geq 76$ years).

2.3. Statistical Analysis. The numbers of overall cases, metastatic cases, and cases with LM were summarized according to primary cancer, with median survival and interquartile range for LM cases. Survival analysis was performed using Kaplan-Meier curves. Additionally, the crude incidences of LM and the incidence of LM overall metastases were calculated. A multivariate logistics regression model was applied to filter out risk factors for cancer patients with LM. Forest plots were used to compare the impact of with lung metastases versus without lung metastases alone among different primary caner sites subgroups. All data analysis was performed using SPSS 23.0 (IBM Corporation, Armonk, NY, USA). All statistical tests were performed two-sided. $P<0.05$ was considered to be statistically significant.

\section{Results}

3.1. Incidence of LM Based on Clinicopathological Characteristics. We enrolled 1,525,441 eligible patients with LM diagnosed between 2010 and 2016 from the SEER database. The basic characteristics of cancer patients with or without LM are depicted in Table 1 . Among 1,525,441 patients, 47,537 (3.12\%) had LM at initial diagnosis. The incidence of LM in elderly, middle-aged, and young patients was $3.72 \%, 3.01 \%$, and $2.95 \%$, respectively. The incidence of LM was higher in men than in women (3.23\% versus $3.01 \%)$. From T1 to T4 stage, patients with later stages had a higher incidence of $\operatorname{LM}(0.79 \%, 2.02 \%, 4.31 \%$, and $9.77 \%$, respectively). The incidence of LM in patients with N0, N1, N2, and N3 subtypes was $1.54 \%, 6.70 \%, 5.25 \%$, and $7.77 \%$, respectively. The incidence of LM in insured versus uninsured patients was $3.15 \%$ versus $6.0 \%$. The incidence of LM in unmarried versus married patients was $4.14 \%$ versus $2.69 \%$.

\subsection{Risk Factors for Developing LM Based on Multivariate} Logistic Regression. Factors associated with LM formation included age, sex, race, marital status, insurance status, $\mathrm{T}$ stage, and $\mathrm{N}$ stage (Table 2). Multivariate logistic regression analysis showed that younger patients (odds ratio (OR): 0.92, 95\% confidence interval (CI): 0.89-0.96; $P<0.001$ ), male sex (OR: 1.04, 95\% CI: 1.02-1.06; $P<0.001$ ), later T stage (OR: 4.48, 95\% CI: 4.31-4.66; $P<0.001$ ), later $\mathrm{N}$ stage (OR: 2.01, 95\% CI: 1.89-2.15; $P<0.001$ ), Caucasian (OR: 0.93, 95\% CI: 0.90-0.96; $P<0.001$ ), uninsured (OR: 1.34, 95\% CI: 1.27-1.40; $P<0.001$ ), and unmarried (OR: 1.28 , 95\% CI: $1.25-1.31 ; P<0.001)$ were significantly positively associated with $\mathrm{LM}$ at initial diagnosis.

\subsection{Incidence of LM Based on Primary Cancer Sites.} Patients with LM have different primary cancer sites. The leading eight incidences of LM were observed in bone cancer (11.91\%), pancreatic cancer $(11.19 \%)$, other gastrointestinal cancer $(10.88 \%)$, esophageal cancer $(10.19 \%)$, kidney cancer $(8.78 \%)$, biliary tract cancer $(8.52 \%)$, sarcoma $(8.40 \%)$, and liver cancer (8.39\%) (Figure 1(a) and Table 3 ). The lungs are the major site of metastasis from testicular cancer $(67.51 \%)$, bone cancer $(62.91 \%)$, thyroid cancer $(56.37 \%)$, endometrial cancer $(54.32 \%)$, other gynecological cancer $(52.10 \%)$, sarcoma (49.51\%), cervical cancer (47.14\%), and head and neck 
TABLE 1: Clinicopathological characteristics of new diagnosis cancer patients with and without lung metastases.

\begin{tabular}{|c|c|c|c|c|c|}
\hline \multirow{3}{*}{ Patients' characteristics } & \multicolumn{4}{|c|}{$\begin{array}{c}\text { No. of new diagnosis cancer } \\
\text { patients }\end{array}$} & \multirow{3}{*}{$\begin{array}{l}\text { Total } \\
\qquad N\end{array}$} \\
\hline & \multicolumn{2}{|c|}{$\begin{array}{l}\text { With lung } \\
\text { metastases }\end{array}$} & \multicolumn{2}{|c|}{$\begin{array}{c}\text { Without lung } \\
\text { metastases }\end{array}$} & \\
\hline & $N$ & $\%$ & $N$ & $\%$ & \\
\hline All patients & 47537 & 3.12 & 1477904 & 96.88 & 1525441 \\
\hline $\begin{array}{l}\text { Age at diagnosis } \\
\text { Elderly } \\
\text { Middle-aged } \\
\text { Young }\end{array}$ & $\begin{array}{c}9132 \\
32581 \\
5824 \\
\end{array}$ & $\begin{array}{l}3.72 \\
3.01 \\
2.95 \\
\end{array}$ & $\begin{array}{c}236053 \\
1050441 \\
191410 \\
\end{array}$ & $\begin{array}{l}96.28 \\
96.99 \\
97.05 \\
\end{array}$ & $\begin{array}{c}245185 \\
1083022 \\
197234 \\
\end{array}$ \\
\hline $\begin{array}{l}\text { Sex } \\
\text { Male } \\
\text { Female } \\
\end{array}$ & $\begin{array}{l}24004 \\
23533 \\
\end{array}$ & $\begin{array}{l}3.23 \\
3.01 \\
\end{array}$ & $\begin{array}{l}718610 \\
759294 \\
\end{array}$ & $\begin{array}{l}96.77 \\
96.99 \\
\end{array}$ & $\begin{array}{l}742614 \\
782827 \\
\end{array}$ \\
\hline $\begin{array}{l}\text { T } \\
\text { T1 } \\
\text { T2 } \\
\text { T3 } \\
\text { T4 } \\
\text { Unknown }\end{array}$ & $\begin{array}{c}5392 \\
7368 \\
10393 \\
9035 \\
15349 \\
\end{array}$ & $\begin{array}{c}0.79 \\
2.02 \\
4.31 \\
9.77 \\
10.52 \\
\end{array}$ & $\begin{array}{c}675382 \\
357589 \\
230908 \\
83432 \\
130593 \\
\end{array}$ & $\begin{array}{l}99.21 \\
97.98 \\
95.69 \\
90.23 \\
89.48 \\
\end{array}$ & $\begin{array}{c}680774 \\
364957 \\
241301 \\
92467 \\
145942 \\
\end{array}$ \\
\hline $\begin{array}{l}N \\
\text { N0 } \\
\text { N1 } \\
\text { N2 } \\
\text { N3 } \\
\text { Unknown }\end{array}$ & $\begin{array}{c}16812 \\
15184 \\
3982 \\
1493 \\
10066 \\
\end{array}$ & $\begin{array}{l}1.54 \\
6.70 \\
5.25 \\
7.77 \\
8.91 \\
\end{array}$ & $\begin{array}{c}1074009 \\
211489 \\
71829 \\
17710 \\
102867 \\
\end{array}$ & $\begin{array}{l}98.46 \\
93.30 \\
94.75 \\
92.23 \\
91.09 \\
\end{array}$ & $\begin{array}{c}1090821 \\
226673 \\
75811 \\
19203 \\
112933 \\
\end{array}$ \\
\hline $\begin{array}{l}\text { Race } \\
\text { White } \\
\text { Black } \\
\text { Others } \\
\text { Unknown }\end{array}$ & $\begin{array}{c}36239 \\
6641 \\
4491 \\
166 \\
\end{array}$ & $\begin{array}{l}3.01 \\
3.90 \\
3.68 \\
0.57 \\
\end{array}$ & $\begin{array}{c}1167620 \\
163747 \\
117476 \\
29061 \\
\end{array}$ & $\begin{array}{l}96.99 \\
96.10 \\
96.32 \\
99.43 \\
\end{array}$ & $\begin{array}{c}1203859 \\
170388 \\
121967 \\
29227 \\
\end{array}$ \\
\hline $\begin{array}{l}\text { Insurance } \\
\text { Insured } \\
\text { Uninsured } \\
\text { Unknown }\end{array}$ & $\begin{array}{c}44285 \\
2362 \\
890 \\
\end{array}$ & $\begin{array}{l}3.15 \\
6.00 \\
1.08 \\
\end{array}$ & $\begin{array}{c}1359405 \\
36998 \\
81501 \\
\end{array}$ & $\begin{array}{l}96.85 \\
94.00 \\
98.92 \\
\end{array}$ & $\begin{array}{c}1403690 \\
39360 \\
82391 \\
\end{array}$ \\
\hline $\begin{array}{l}\text { Marital status } \\
\text { Married } \\
\text { Unmarried } \\
\text { Unknown }\end{array}$ & $\begin{array}{c}22493 \\
22842 \\
2202\end{array}$ & $\begin{array}{l}2.69 \\
4.14 \\
1.59\end{array}$ & $\begin{array}{l}812320 \\
529150 \\
136434\end{array}$ & $\begin{array}{l}97.31 \\
95.86 \\
98.41\end{array}$ & $\begin{array}{l}834813 \\
551992 \\
138636\end{array}$ \\
\hline
\end{tabular}

cancer (46.92\%) (Figure 1(b) and Table 3). The four most common primary cancers were colorectal (19.22\%), kidney (11.64\%), breast $(11.34 \%)$, and pancreatic $(8.92 \%)$ cancer, accounting for $>50 \%$ of all LMs. Moreover, $4.33 \%$ of LM cases originated from the endometrium, 3.99\% from the esophagus, 3.96\% from the liver, and 3.60\% from other organs (Figure 1(c) and Table 3).

3.4. Survival Analysis. The median survival for overall LM cases was 6 months, with the best survival in testicular cancer (19 months), followed by bone (12 months), prostate (12 months), breast (11 months), ovarian (11 months), brain (10 months), anal (8 months), and colorectal (8 months) cancer (Figure 1(d) and Table 3).

Univariate Cox regression analysis compared the hazard ratios (HRs) for mortality in patients with or without LM. Patients with LM had poorer OS compared to those without
TABLE 2: Multivariable logistic regression for the presence of lung metastases at diagnosis by cancer type.

\begin{tabular}{|c|c|c|c|}
\hline \multicolumn{2}{|c|}{ Categories } & OR $(95 \% \mathrm{CI})$ & $p$ \\
\hline \multirow{3}{*}{ Age } & Elderly & Ref & \\
\hline & Middle-aged & $0.90(0.87-0.92)$ & $<0.001$ \\
\hline & Young & $0.92(0.89-0.96)$ & $<0.001$ \\
\hline \multirow{2}{*}{ Sex } & Female & Ref & \\
\hline & Male & $1.04(1.02-1.06)$ & $<0.001$ \\
\hline \multirow{5}{*}{$\mathrm{T}$} & $\mathrm{T} 1$ & Ref & \\
\hline & $\mathrm{T} 2$ & $1.93(1.86-2.01)$ & $<0.001$ \\
\hline & T3 & $3.01(2.91-3.12)$ & $<0.001$ \\
\hline & $\mathrm{T} 4$ & $4.48(4.31-4.66)$ & $<0.001$ \\
\hline & Unknown & $4.57(4.40-4.76)$ & $<0.001$ \\
\hline \multirow{5}{*}{$\mathrm{N}$} & N0 & Ref & \\
\hline & N1 & $1.91(1.86-1.96)$ & $<0.001$ \\
\hline & $\mathrm{N} 2$ & $1.43(1.38-1.49)$ & $<0.001$ \\
\hline & N3 & $2.01(1.89-2.15)$ & $<0.001$ \\
\hline & Unknown & $1.50(1.45-1.55)$ & $<0.001$ \\
\hline \multirow{4}{*}{ Race } & Black & Ref & \\
\hline & White & $0.93(0.90-0.96)$ & $<0.001$ \\
\hline & Others & $1.08(1.03-1.06)$ & $<0.001$ \\
\hline & Unknown & $0.37(0.32-0.44)$ & $<0.001$ \\
\hline \multirow{3}{*}{ Insurance } & Insured & Ref & \\
\hline & Uninsured & $1.34(1.27-1.40)$ & $<0.001$ \\
\hline & Unknown & $0.60(0.56-0.65)$ & $<0.001$ \\
\hline \multirow{3}{*}{ Marital status } & Married & Ref & \\
\hline & Unmarried & $1.28(1.25-1.31)$ & $<0.001$ \\
\hline & Unknown & $0.86(0.82-0.91)$ & $<0.001$ \\
\hline
\end{tabular}

LM $(\mathrm{HR}=7.75 ; P<0.001)$ (Figure 2). A Cox regression model was used to analyze HR and 95\% CI stratified by primary cancer site. For most primary cancer sites, LM had a significant negative impact on OS, except for patients with primary brain cancer $(P=0.09)$ (Figure 2$)$. Forest plots showed that the following primary cancer sites had the greatest negative influence on OS: thyroid $(\mathrm{HR}=44.79$; $P<0.001)$, melanoma $(\mathrm{HR}=24.26 ; P<0.001)$, prostate $(\mathrm{HR}=16.0 ; P<0.001)$, breast $(\mathrm{HR}=13.46 ; P<0.001)$, endometrium $(\mathrm{HR}=12.64 ; \quad P<0.001)$, testis $(\mathrm{HR}=12.31$; $P<0.001)$, and kidney $(\mathrm{HR}=11.33 ; P<0.001)$.

\section{Discussion}

In the current study, our data were obtained from the SEER database, which covers $\sim 28 \%$ of the general population in USA; the demonstrated trends are of great representativeness and generalizability. We described the basic clinical characteristics of cancer patients with or without LM and explored the risk factors for developing LM. Multivariate logistic regression revealed that male sex, older patients, later $\mathrm{T} / \mathrm{N}$ stage, unmarried status, and lack of insurance were the independent risk factors for LM. These risk factors may help customize lung monitoring and clinical decision-making.

We performed a comprehensive analysis of the incidence and prognosis of LM at initial diagnosis, according to primary cancer site. LM has been shown to originate most often from breast, followed by rectum, cervix, and stomach [5]. In a study of 5,206 patients who underwent lung metastasectomy, $\sim 43 \%$ of LMs were from epithelial cell tumors, 


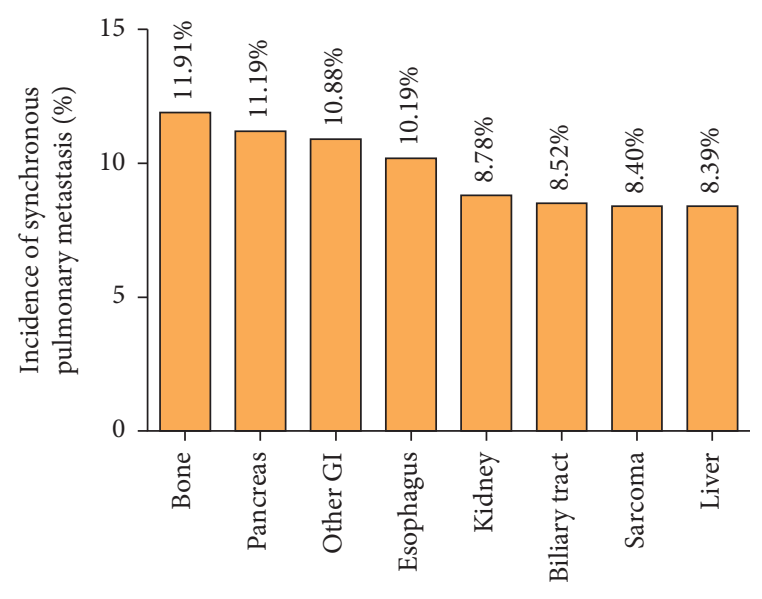

(a)

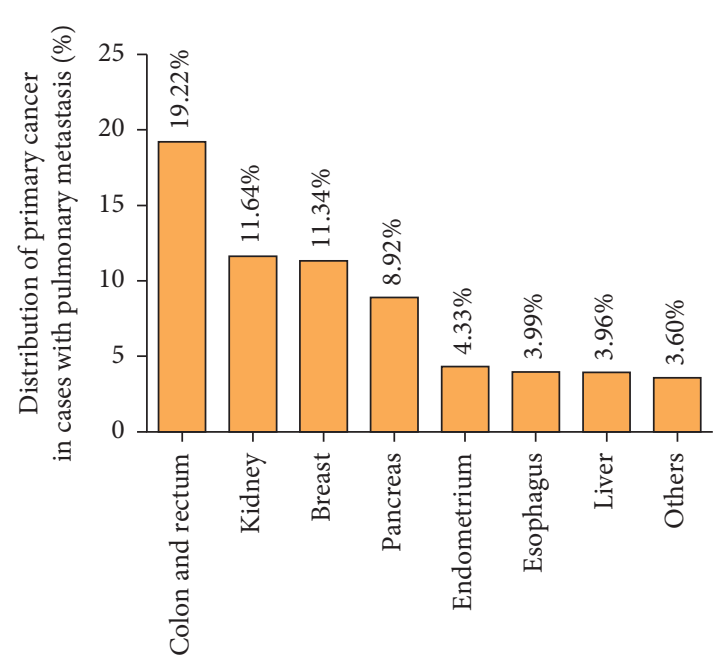

(c)

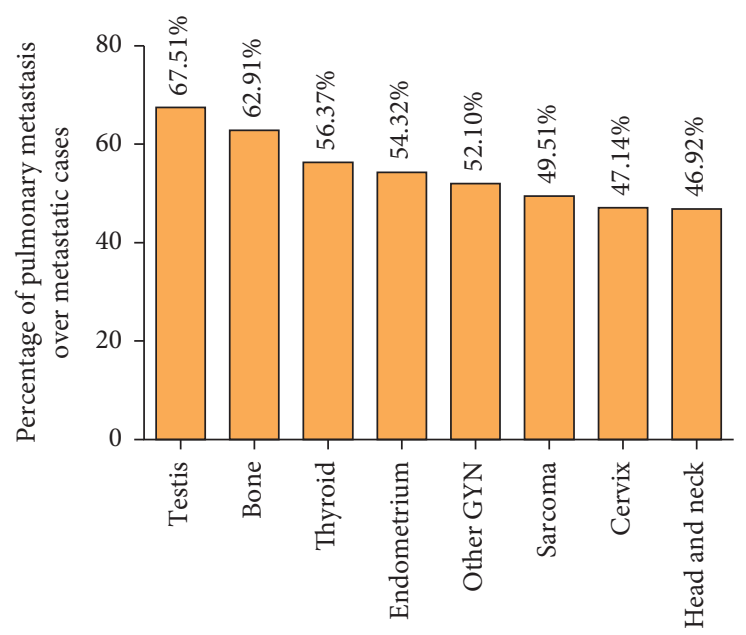

(b)

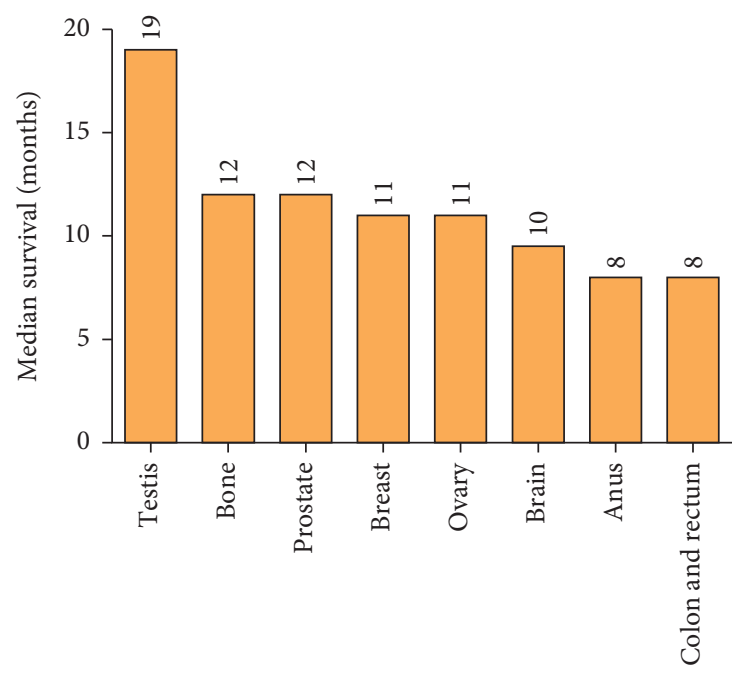

(d)

FIGURE 1: Prevalence and prognosis of LM according to primary cancer type. (a) Incidence of synchronous LM in different cancer types in all cancer patients (including metastatic and nonmetastatic cancer). (b) Incidence of synchronous LM in different cancer types in patients with metastatic lesions. (c) Distribution of primary cancer types in patients with LM. (d) Median survival of cancer patients with LM.

sarcomas (42\%), germ cell tumors (7\%), and melanoma (6\%) [4]. 4572 patients were enrolled from the International Registry of Lung Metastases. Survival analysis stratified by pathological patterns showed that the 5-year survival rate was $36 \%$ in patients with epithelial tumors, and 10-year survival rate was $26 \%$ in patients with sarcomas. Our research showed that LM was most commonly from colorectal cancer, followed by kidney, breast, and pancreatic cancer.

Our results showed that median OS for LM cases overall was 6 months, with the best for testicular cancer, followed by bone, prostate, breast, ovarian, brain, anal, and colorectal cancer. We found that patients with LM had poorer OS compared to those without LM. In the subgroup analysis, LM from brain cancer did not affect prognosis. For most primary tumors, the risk of mortality is significantly increased when LM occurs. Mortality was increased most significantly for LM from thyroid cancer, melanoma, and prostate, breast, endometrial, testicular, and kidney cancer. Therefore, for clinicians, early detection of LM is important for clinical practice to reduce the risk of mortality and disease burden in cancer patients.

Colorectal cancer was the most common primary cancer for LM in our study, which deserves more attention. For patients with colorectal cancer, the liver and lungs were top two metastatic sites. A previous study [10] has described the pattern of distant metastases in colorectal cancer. Rectal cancer had a higher incidence of LM compared to colon cancer, which is similar to our results, especially for N1 stage rectal cancer. Similar results have been reported in stage IV colorectal cancer [11]. Compared to patients with metastases in other organs such as the liver, bone, and brain, patients with only LM have better OS, specifically among those with KRAS mutant tumors [12]. In patients with LM, colorectal cancer cells usually initially enter the general circulation, followed by infiltration of the lung parenchyma, killing the lung capillary cells. This process involves parathyroid hormone-like hormone (PTHLH) and possibly necroptosis. Chemokines derived from exosomes may promote 
TABLE 3: Numbers of all cases, metastatic cases, and cases with pulmonary metastasis and incidence, distribution, and prognosis of lung metastasis by cancer type.

\begin{tabular}{|c|c|c|c|c|c|c|c|c|}
\hline \multicolumn{2}{|c|}{ Categories } & \multicolumn{3}{|c|}{ Numbers of cases } & \multicolumn{2}{|c|}{ Incidence (\%) } & \multirow{2}{*}{$\begin{array}{c}\text { Distribution (\%) } \\
\text { Distribution of LM } \\
\text { cases }\end{array}$} & \multirow{2}{*}{$\begin{array}{c}\text { Median survival with } \\
\text { IQR } \\
\text { LM }\end{array}$} \\
\hline Site & Subtype & All & Metastasis & LM & LM & $\begin{array}{c}\text { LM/ } \\
\text { metastasis }\end{array}$ & & \\
\hline \multirow{3}{*}{$\begin{array}{l}\text { Brain } \\
\text { Head and } \\
\text { neck } \\
\text { Thyroid }\end{array}$} & Brain & 27336 & 280 & 18 & 0.07 & 6.43 & 0.04 & $10(3-20)$ \\
\hline & Head and neck & 65472 & 2969 & 1393 & 2.13 & 46.92 & 2.93 & $7(3-15)$ \\
\hline & Thyroid & 71996 & 1506 & 849 & 1.18 & 56.37 & 1.79 & $7(2-26)$ \\
\hline \multirow{5}{*}{ Breast } & All breast & 317800 & 22087 & 5391 & 1.70 & 24.41 & 11.34 & $11(3-27)$ \\
\hline & HR+/HER2- & 214981 & 11133 & 2474 & 1.15 & 22.22 & 5.20 & $14(4-31)$ \\
\hline & HR+/HER2+ & 33561 & 3683 & 836 & 2.49 & 22.70 & 1.76 & $17(5-31)$ \\
\hline & HR-/HER2+ & 14343 & 2023 & 534 & 3.72 & 26.40 & 1.12 & $11(3-25)$ \\
\hline & HR-/HER2- & 33931 & 2648 & 886 & 2.61 & 33.46 & 1.86 & $8(2-15)$ \\
\hline \multirow{16}{*}{ GI } & Unknown & 20984 & 2600 & 663 & 3.16 & 25.50 & 1.39 & $4(1-19)$ \\
\hline & Esophagus & 18635 & 6886 & 1899 & 10.19 & 27.58 & 3.99 & $3(1-8)$ \\
\hline & Stomach & 32352 & 8431 & 1707 & 5.28 & 20.25 & 3.59 & $7(2-19)$ \\
\hline & Small intestine & 9925 & 1965 & 231 & 2.33 & 11.76 & 0.49 & $5(1-11.5)$ \\
\hline & Colon and rectum & 174311 & 38217 & 9138 & 5.24 & 23.91 & 19.22 & $8(2-19)$ \\
\hline & Colon & 132385 & 29604 & 6491 & 4.90 & 21.93 & 13.65 & $9(2-23)$ \\
\hline & Rectum & 41926 & 8613 & 2647 & 6.31 & 30.73 & 5.57 & $10(4-21)$ \\
\hline & Anus & 8389 & 608 & 190 & 2.26 & 31.25 & 0.40 & $8(4-15)$ \\
\hline & Liver & 22420 & 4259 & 1881 & 8.39 & 44.17 & 3.96 & $2(0-5)$ \\
\hline & Biliary tract & 8687 & 3148 & 740 & 8.52 & 23.51 & 1.56 & $3(1-7.5)$ \\
\hline & Pancreas & 37878 & 21924 & 4238 & 11.19 & 19.33 & 8.92 & $2(1-6)$ \\
\hline & Head of pancreas & 17871 & 6939 & 1213 & 6.79 & 17.48 & 2.55 & $3(1-7)$ \\
\hline & Body of pancreas & 4956 & 3265 & 653 & 13.18 & 20.00 & 1.37 & $3(1-7)$ \\
\hline & Tail of pancreas & 6693 & 5139 & 983 & 14.69 & 19.13 & 2.07 & $2(1-5)$ \\
\hline & $\begin{array}{l}\text { Unspecified } \\
\text { pancreas }\end{array}$ & 8358 & 6581 & 1389 & 16.62 & 21.11 & 2.92 & $2(1-5)$ \\
\hline & Other GI & 7474 & 4007 & 813 & 10.88 & 20.29 & 1.71 & $2(0-6)$ \\
\hline \multirow{4}{*}{ GYN } & Cervix & 17644 & 1661 & 783 & 4.44 & 47.14 & 1.65 & $5(2-12)$ \\
\hline & Endometrium & 74852 & 3785 & 2056 & 2.75 & 54.32 & 4.33 & $6(2-14)$ \\
\hline & Ovary & 26483 & 3302 & 1329 & 5.02 & 40.25 & 2.80 & $11(2-25)$ \\
\hline & Other GYN & 11173 & 869 & 452 & 4.05 & 52.01 & 0.95 & $7(2-21)$ \\
\hline \multirow{5}{*}{ GU } & Kidney & 62992 & 11951 & 5531 & 8.78 & 46.28 & 11.64 & $6(2-16)$ \\
\hline & Bladder & 72767 & 3061 & 1116 & 1.53 & 36.46 & 2.35 & $3(1-8)$ \\
\hline & Prostate & 289240 & 14981 & 1247 & 0.43 & 8.32 & 2.62 & $12(4-26)$ \\
\hline & Testis & 15736 & 1668 & 1126 & 7.16 & 67.51 & 2.37 & $19(7-44)$ \\
\hline & Other GU & 7413 & 1198 & 468 & 6.31 & 39.07 & 0.98 & $4(2-9)$ \\
\hline Bone & Bone & 4458 & 844 & 531 & 11.91 & 62.91 & 1.12 & $12(5-26)$ \\
\hline Skin & Melanoma & 99708 & 2973 & 1067 & 1.07 & 35.89 & 2.24 & $4(2-10)$ \\
\hline Sarcoma & Sarcoma & 19397 & 3292 & 1630 & 8.40 & 49.51 & 3.43 & $7(2-19)$ \\
\hline Others & Others & 20903 & 5972 & 1713 & 8.19 & 28.68 & 3.60 & $3(1-9)$ \\
\hline All & All & 1525441 & 171844 & 47537 & 3.1 & 27.7 & 100 & $6(2-16)$ \\
\hline
\end{tabular}

LM: lung metastases; GI: gastrointestinal cancer; GYN: gynecologic cancer; GU: genitourinary cancer; IQR: interquartile range.

colorectal cancer cell metastasis to the lungs [9]. Colorectal cancer cells, via a macrophage-dependent pathway, release microparticles to remodel the lung parenchyma and create an altered inflammatory and mechanical response to tumor cell invasion [13]. The specific mechanism of colorectal cancer metastasis to the lungs is still unknown.

Breast cancer is the most common malignant disease in women [1]. More importantly, breast cancer had one of the highest incidences of LM in our research. LM significantly increased the mortality of breast cancer patients. A previous study demonstrated that most breast-cancer-related deaths were related to the occurrence of metastases [14]. Usually decades after initial diagnosis of primary cancer, over half of breast cancer patients will develop metastases, which severely affects disease management [15]. Besides bone, the lungs are the most frequent site of metastasis in breast cancer patients. We identified 317,800 breast cancer patients with $\mathrm{LM}$, representing $1.69 \%$ of the entire cases and $24.4 \%$ of the subgroup with metastases. This is similar to a recent research [8]. Clinical research has shown that different molecular characteristics affect organ-specific metastatic patterns. $\mathrm{HR}^{-} / \mathrm{HER} 2^{+}$and triple-negative breast cancer patients have the highest incidence of metastasis. Triple-negative patients have poor survival and usually respond poorly to hormonal therapy [16]. Recently, more attention has been paid to the underlying molecular mechanisms that play an important 


\begin{tabular}{|c|c|c|c|c|c|c|c|}
\hline Cancer type & Number & LM & LM (\%) & & Hazarc & d ratio $(95 \% \mathrm{CI})$ & $P$.value \\
\hline All cancers & 1525441 & 47537 & 3.12 & - & 7.75 & $(7.66-7.84)$ & $<0.001$ \\
\hline Thyroid & 71996 & 849 & 1.18 & & 44.79 & $(40.46-49.59)$ & $<0.001$ \\
\hline Melanoma & 99708 & 1067 & 1.07 & $\longmapsto$ & 24.26 & $(22.49-26.18)$ & $<0.001$ \\
\hline Prostate & 289240 & 1247 & 0.43 & $1-1$ & 16.00 & $(14.80-17.29)$ & $<0.001$ \\
\hline Breast & 317800 & 5391 & 1.70 & |ө1 & 13.46 & $(12.98-13.95)$ & $<0.001$ \\
\hline Endometrium & 74852 & 2056 & 2.75 & юr & 12.64 & $(11.97-13.34)$ & $<0.001$ \\
\hline Testis & 15736 & 1126 & 7.16 & $\longmapsto$ & 12.31 & $(10.54-14.38)$ & $<0.001$ \\
\hline Kidney & 62992 & 5531 & 8.78 & IE & 11.33 & $(10.9-11.79)$ & $<0.001$ \\
\hline Bladder & 72767 & 1116 & 1.53 & 19 & 11.11 & $(10.4-11.87)$ & $<0.001$ \\
\hline Cervix & 17644 & 783 & 4.44 & rer & 8.13 & $(7.46-8.85)$ & $<0.001$ \\
\hline Anus & 8389 & 190 & 2.26 & $1-1$ & 6.65 & $(5.59-7.91)$ & $<0.001$ \\
\hline Other GU & 7413 & 468 & 6.31 & юr & 5.79 & $(5.19-6.45)$ & $<0.001$ \\
\hline Head and neck & 65472 & 1393 & 2.13 & 目 & 5.42 & $(5.09-5.77)$ & $<0.001$ \\
\hline Small intestine & 9925 & 231 & 2.33 & rer & 5.05 & $(4.33-5.9)$ & $<0.001$ \\
\hline Colon and rectum & 174311 & 9138 & 5.24 & (1) & 4.76 & $(4.64-4.89)$ & $<0.001$ \\
\hline Sarcoma & 19397 & 1630 & 8.40 & 目 & 4.61 & $(4.32-4.91)$ & $<0.001$ \\
\hline Bone & 4458 & 531 & 11.91 & 1버 & 4.31 & $(3.77-4.92)$ & $<0.001$ \\
\hline Other GYN & 11173 & 452 & 4.05 & |ө & 3.53 & $(3.11-4.01)$ & $<0.001$ \\
\hline Others & 20903 & 1713 & 8.19 & 日 & 3.29 & $(3.09-3.5)$ & $<0.001$ \\
\hline Ovary & 26483 & 1329 & 5.02 & 日 & 3.23 & $(3.01-3.46)$ & $<0.001$ \\
\hline Stomach & 32352 & 1707 & 5.28 & $\theta$ & 3.06 & $(2.9-3.23)$ & $<0.001$ \\
\hline Liver & 22420 & 1881 & 8.39 & $\theta$ & 2.89 & $(2.74-3.05)$ & $<0.001$ \\
\hline Biliary tract & 8687 & 740 & 8.52 & $\theta$ & 2.72 & $(2.5-2.95)$ & $<0.001$ \\
\hline Esophagus & 18635 & 1899 & 10.19 & e & 2.59 & $(2.46-2.73)$ & $<0.001$ \\
\hline Other GI & 7474 & 813 & 10.88 & $\theta$ & 2.36 & $(2.18-2.55)$ & $<0.001$ \\
\hline Pancreas & 37878 & 4238 & 11.19 & $\bullet$ & 2.26 & $(2.18-2.34)$ & $<0.001$ \\
\hline Brain & 27336 & 18 & 0.07 & ⺊r & 1.58 & $(0.94-2.56)$ & 0.09 \\
\hline
\end{tabular}

FIGURE 2: Forest plots depict OS among primary cancer patients with or without LM. GI: gastrointestinal cancer; GYN: gynecological cancer; GU: genitourinary cancer.

role in the organ-specific metastasis of breast cancer cells [15].

Previous studies have demonstrated that the liver, lung, bone, brain, and distant lymph nodes are the common sites of metastases from pancreatic adenocarcinoma [17-20]. In $19.9 \%$ of patients, LMs were found at initial diagnosis of primary cancer. Compared to liver metastasis, patients with LM have better OS. In renal cell carcinoma patients, the lungs are the most common site of metastasis [21, 22]. Surgical intervention may improve OS significantly in renal cell carcinoma patients with LM [6].

The above tumors are more prone to LM, which is accompanied by a complicated pathological process. The process of tumor metastasis is not randomly generated and is regulated by multiple factors, including microenvironmental, cellular, and molecular factors. Circulation patterns are important for circulating tumor cells (CTCs) to mechanically arrest in the capillary networks they encounter. Due to its high vascular flow, hypoxia, and inflammation, the lungs are an example of the most common metastatic targets, with $\sim 10.7 \%$ of all primary malignancies targeting this site [5]. When tumor cells leave their primary site and enter the venous drainage of the organ, it is likely that the first metastatic foci will develop in the filtering organ.

When the tumor grows malignantly in situ, it begins to infiltrate the surrounding tissues and enters the circulation through the blood vessel walls to form CTCs [2]. These CTCs reach the target before the metastasis of the organ, the metastasis organ will first form the premetastasis microenvironment, and the primary tumor secretes a large number of factors, including exosomes [23, 24], cytokines [2], and chemokines [9], which recruit bone-marrow-derived cells to metastatic organs and change the extracellular matrix environment of the metastatic organs. The arrival of CTC transplantation provides a living soil. How the factors secreted by these malignant tumor cells affect the normal lung tissue and how they promote LM in the premetastasis microenvironment are still unclear.

Although the current study had some novel findings, it still had some limitations. First, we only obtained qualitative information about LM status from the SEER database rather than specific quantitative information for LM lesions, including the number and size of lesions. Second, the lack of molecular-related information made it impossible to further analyze the relevant mechanisms of LM. Third, underestimation of incidence may occur in cancer types in which routine LM screening is not adopted.

\section{Conclusion}

The current study provided generalizable and representative epidemiological data for LM according to clinicopathological 
factors and primary cancer sites. Multivariate logistic regression revealed that male sex, older patients, later T/N stage, unmarried status, and lack of insurance were risk factors for LM. We found that patients with LM had higher HR for mortality compared to those without LM, except for brain cancer patients. Clinicians should pay more attention to the occurrence of LM, especially for those with a significantly increased HR for mortality, such as thyroid cancer, melanoma, and prostate cancer. These data not only help medical practitioners tailor screening protocols and design clinical trials but also give an approximation of the public disease burden for policy-makers.

\section{Abbreviations}

LM: $\quad$ Lung metastases

SEER: Surveillance, Epidemiology, and End Results

OS: Overall survival

HR: Hazard ratio

IQR: Interquartile range

CTCs: Circulating tumor cells

GI: Gastrointestinal cancer

GYN: Gynecologic cancer.

\section{Data Availability}

The datasets generated and/or analyzed during the current study are available in the Surveillance, Epidemiology, and End Results Program repository (https://seer.cancer.gov/ data/).

\section{Disclosure}

The funding institutions did not have any roles in the study design, data collection, or analysis.

\section{Conflicts of Interest}

The authors declare that they have no conflicts of interest.

\section{Authors' Contributions}

Xiaohong Liang and Yinan Cheng have made substantial contributions to data collection, data analysis, and manuscript writing. Weijun Zhou, Jun Ni, and Zhengping Yan performed data analysis. Yuqing Li contributed to acquisition and interpretation of data. Gaohua Feng designed the study. All authors read and approved the final manuscript.

\section{Acknowledgments}

The authors acknowledge the efforts of the Surveillance, Epidemiology, and End Results (SEER) Program tumor registries in the creation of the SEER database. This study was supported by grants from Zhangjiagang City Science and Technology Plan Project (ZKS2046) and Zhangjiagang City Health Youth Science and Technology Project (ZJGQNKJ202034).

\section{References}

[1] R. L. Siegel, K. D. Miller, and A. Jemal, "Cancer statistics, 2020," CA: A Cancer Journal for Clinicians, vol. 70, no. 1, pp. 7-30, 2020.

[2] S. Izraely and I. P. Witz, "Site-specific metastasis: a cooperation between cancer cells and the metastatic microenvironment," International Journal of Cancer, vol. 148, no. 6, pp. 1308-1322, 2020.

[3] J. Puchalski, "Pulmonary manifestations of solid non-pulmonary malignancies," Clinics in Chest Medicine, vol. 38, no. 2, pp. 177-186, 2017.

[4] U. Pastorino, M. Buyse, G. Friedel et al., "Long-term results of lung metastasectomy: prognostic analyses based on 5206 cases," The Journal of Thoracic and Cardiovascular Surgery, vol. 113, no. 1, pp. 37-49, 1997.

[5] G. Disibio and S. W. French, "Metastatic patterns of cancers: results from a large autopsy study," Archives of Pathology \& Laboratory Medicine, vol. 132, no. 6, pp. 931-939, 2008.

[6] S. Lin, Y. Zheng, Z. Qin et al., "Surgical intervention in renal cell carcinoma patients with lung and bronchus metastasis is associated with longer survival time: a population-based analysis," Annals of Translational Medicine, vol. 7, no. 14, p. 323, 2019.

[7] Y. Huang, M. Zhao, J. Yin et al., "Pulmonary metastasis in newly diagnosed colon-rectal cancer: a population-based nomogram study," International Journal of Colorectal Disease, vol. 34, no. 5, pp. 867-878, 2019.

[8] S. Chen, J. Yang, Y. Liu, H. You, Y. Dong, and J. Lyu, "Prognostic factors and survival outcomes according to tumor subtype in patients with breast cancer lung metastases," PeerJ, vol. 7, p. e8298, 2019.

[9] M. Wang, X. Yang, M. Wei, and Z. Wang, "The role of CXCL12 Axis in lung metastasis of colorectal cancer," Journal of Cancer, vol. 9, no. 21, pp. 3898-3903, 2018.

[10] M. Qiu, J. Hu, D. Yang, D. P. Cosgrove, and R. Xu, "Pattern of distant metastases in colorectal cancer: a SEER based study," Oncotarget, vol. 6, no. 36, pp. 38658-38666, 2015.

[11] J. R. Robinson, P. A. Newcomb, S. Hardikar, S. A. Cohen, and A. I. Phipps, "Stage IV colorectal cancer primary site and patterns of distant metastasis," Cancer Epidemiology, vol. 48, pp. 92-95, 2017.

[12] O. Margalit, E. Shacham-Shmueli, Y. R. Lawrence et al., "Lung metastasis predicts better prognosis in metastatic colorectal cancer with mutated KRAS," Clinical Colorectal Cancer, vol. 18, no. 3, pp. e300-e307, 2019.

[13] H. Zhang, Y. Yu, L. Zhou et al., "Circulating tumor microparticles promote lung metastasis by reprogramming inflammatory and mechanical niches via a macrophagedependent pathway," Cancer Immunology Research, vol. 6, no. 9, pp. 1046-1056, 2018.

[14] V. Sopik and S. A. Narod, "The relationship between tumour size, nodal status and distant metastases: on the origins of breast cancer," Breast Cancer Research and Treatment, vol. 170, no. 3, pp. 647-656, 2018.

[15] M. Yousefi, R. Nosrati, A. Salmaninejad, S. Dehghani, A. Shahryari, and A. Saberi, "Organ-specific metastasis of breast cancer: molecular and cellular mechanisms underlying lung metastasis," Cellular Oncology, vol. 41, no. 2, pp. 123-140, 2018.

[16] J. T. L. Berry, L. E. Muñoz, R. M. Rodríguez Stewart, P. Selvaraj, and B. A. Mainou, "Doxorubicin conjugation to reovirus improves oncolytic efficacy in triple-negative breast cancer," Molecular Therapy-Oncolytics, vol. 18, pp. 556-572, 2020. 
[17] H. Oweira, U. Petrausch, D. Helbling et al., "Prognostic value of site-specific metastases in pancreatic adenocarcinoma: a Surveillance Epidemiology and End Results database analysis," World Journal of Gastroenterology, vol. 23, no. 10, pp. 1872-1880, 2017.

[18] A. Wang-Gillam, R. A. Hubner, J. T. Siveke et al., "NAPOLI-1 phase 3 study of liposomal irinotecan in metastatic pancreatic cancer: final overall survival analysis and characteristics of long-term survivors," European Journal of Cancer, vol. 108, pp. 78-87, 2019.

[19] R. Yewale, B. Ramakrishna, K. Vijaykumar et al., "Pancreatic adenocarcinoma with synchronous colonic metastases," ACG Case Reports Journal, vol. 7, no. 1, p. e00299, 2020.

[20] P. J. Broadhurst and A. R. Hart, "An observational study to justify and plan a future phase III randomized controlled trial of metformin in improving overall survival in patients with inoperable pancreatic cancer without liver metastases," Journal of Cancer Research and Clinical Oncology, vol. 146, no. 5, pp. 1369-1375, 2020.

[21] O. Abdel-Rahman, "Clinical correlates and prognostic value of different metastatic sites in metastatic renal cell carcinoma," Future Oncology, vol. 13, no. 22, pp. 1967-1980, 2017.

[22] T. Chandrasekar, Z. Klaassen, H. Goldberg, G. S. Kulkarni, R. J. Hamilton, and N. E. Fleshner, "Metastatic renal cell carcinoma: patterns and predictors of metastases-A contemporary population-based series," Urologic Oncology, vol. 35, pp. 661.e7-661.e14, 2017.

[23] A. Hoshino, B. Costa-Silva, T.-L. Shen et al., "Tumour exosome integrins determine organotropic metastasis," Nature, vol. 527, no. 7578, pp. 329-335, 2015.

[24] I. Wortzel, S. Dror, C. M. Kenific, and D. Lyden, "Exosomemediated metastasis: communication from a distance," $D e$ velopmental Cell, vol. 49, no. 3, pp. 347-360, 2019. 